\title{
Early intervention for relapse in schizophrenia: results of a 12-month randomized controlled trial of cognitive behavioural therapy
}

\author{
A. GUMLEY, ${ }^{1}$ M. O'GRADY, L. McNAY, J. REILLY, K. POWER AND J. NORRIE \\ From the Department of Psychological Medicine, University of Glasgow, Gartnavel Royal Hospital, Robertson \\ Centre for Biostatistics, University of Glasgow and Greater Glasgow Primary Care Trust, Glasgow; Ayrshire \\ and Arran Primary Care Trust; and Department of Psychology, University of Stirling
}

\begin{abstract}
Background. The paper describes a randomized controlled trial of targeting cognitive behavioural therapy (CBT) during prodromal or early signs of relapse in schizophrenia. We hypothesized that CBT would result in reduced admission and relapse, reduced positive and negative symptoms, and improved social functioning.
\end{abstract}

Method. A total of 144 participants with schizophrenia or a related disorder were randomized to receive either treatment as usual (TAU) $(N=72)$ or CBT + TAU $(N=72)$. Participants were prospectively followed up between entry and 12 months.

Results. At 12 months, $11(15 \cdot 3 \%)$ participants in the CBT group were admitted to hospital compared to $19(26 \cdot 4 \%)$ of the TAU group (hazard ratio $=0 \cdot 53, P=0 \cdot 10,95 \%$ CI $0 \cdot 25,1 \cdot 10)$. A total of $13(18 \cdot 1 \%)$ participants in CBT relapsed compared to $25(34.7 \%)$ in TAU (hazard ratio $=0 \cdot 47$, $P<0 \cdot 05,95 \%$ CI $0 \cdot 24,0 \cdot 92$ ). In addition, the CBT group showed significantly greater improvement in positive symptoms, negative symptoms, global psychopathology, performance of independent functions and prosocial activities.

Conclusions. The study provides evidence for the feasibility and effectiveness for targeting CBT on the appearance of early signs of relapse in schizophrenia. The results are discussed in context of the study's methodological limitations.

\section{INTRODUCTION}

There is growing evidence that CBT is effective in reducing the severity of positive and negative symptoms associated with schizophrenia (Tarrier et al. 1993, 1998; Drury et al. 1996a,b; Kuipers et al. 1997; Pinto et al. 1999; Sensky et al. 2000; Turkington et al. 2002). Four trials provide post-treatment follow-up (Kuipers et al. 1998; Drury et al. 2000; Sensky et al. 2000; Tarrier et al. 1999, 2000). Kuipers et al. (1998) and Sensky et al. (2000) do not report relapse

\footnotetext{
1 Address for correspondence: Dr Andrew Gumley, University of Glasgow, Department of Psychological Medicine, Academic Centre, Garnavel Royal Hospital, 1055 Great Western Road, Glasgow G12 $\mathrm{OXH}$.
}

rates for their participants. Kuipers et al. (1998) found that at 9 months those who had received CBT continued to show improvements in delusional distress and frequency of hallucinations. Sensky et al. (2000) found that the CBT group continued to improve on measures of positive symptoms, depression and negative symptoms. Tarrier et al. (1999) reported 12month follow-up results for CBT compared to supportive counselling (SC) or routine care (RC). Participants in CBT continued to show significant treatment effects for both positive and negative symptoms. There were no significant differences between the three groups for relapse at this follow-up. At 2 years, Tarrier et al. (2000) found that there were significant differences for 
both CBT and SC over RC for positive and negative symptoms. There was no significant difference between CBT and SC groups. In terms of relapse, there were no significant differences between CBT and SC. These groups were combined for comparison with RC. The number of relapses was greater in the RC group $(11 / 28$, $39 \%)$ compared to the combined group $(13 / 59$, $27 \%$ ). In a 5-year follow-up of 40 participants randomized to either CBT or ATY (recreational activities with informal support), Drury et al. (2000) found no differences between the two groups with regards to number of relapses or admissions, or time spent in acute in-patient facilities. However for those individuals who received $\mathrm{CBT}$ and did not have more than one relapse, the effects of CBT endured. These participants continued to show reduced self-rated delusional conviction, observer rated delusional ideation, thought disorder, hallucinations, and increased perception of control over psychosis.

Therefore, it appears that the effects of CBT on positive and negative symptoms endure over time and that strategies aimed at preventing or minimising relapse should enhance the durability of CBT, or indeed other interventions for schizophrenia. This is especially important given that two prospective studies of first episode schizophrenia (Shepherd et al. 1989; Wiersma et al. 1998) show an increased incidence of drugresistant symptoms following relapse. One welldeveloped strategy for the prevention of relapse in schizophrenia is the monitoring of prodromes or 'early signs' of relapse (Birchwood \& Spencer, 2001). Eight prospective studies of early signs (Subotnik \& Neuchterlein, 1988; Birchwood et al. 1989; Jolley et al. 1990; Marder et al. 1991, 1994; Tarrier et al. 1991; Gaebel et al. 1993; Jorgensen, 1998) confirm that relapse is almost always preceded by non-psychotic symptoms such as anxiety and depression, and low-level psychotic symptoms such as ideas of reference. However, the occurrence of early signs does not necessarily mean that relapse is inevitable. Three studies (Breier \& Strauss, 1983; McCandless-Glimcher et al. 1986; Hultman et al. 1997) show that patients monitor and regulate their symptoms in order to prevent relapse. For example, Hultman et al. (1997) found that patients with a withdrawal-orientated coping style were more likely to relapse than patients who had a socially-orientated coping style. Among patients with bipolar disorder, Lam \& Wong (1997) found that participants spontaneously described using cognitive behavioural strategies to prevent depressive relapse and behavioural strategies to prevent manic relapse. Lam et al. (2001) found that participants who used coping strategies to prevent relapse were less likely to experience either a depressive or a manic relapse during an 18 -month naturalistic study. In a 12 month pilot study of CBT for the prevention of relapse in bipolar disorder, Lam et al. (2000) found that participants who received CBT had fewer bipolar episodes, higher social functioning, less fluctuation in symptoms of mania and depression and improved medication compliance. Perry et al. (1999) evaluated the efficacy of teaching patients with bipolar disorder to identify early signs of relapse and obtain conventional psychiatric treatment. Over 18 months, there was a significant reduction in manic relapses and improvements in overall social functioning and employment for the experimental group.

To date, there have been no controlled trials of CBT for patients with schizophrenia to prevent potential relapses once early signs have been identified, although this idea has been frequently written about (e.g. Birchwood, 1995; Gumley et al. 1999). Based on the preceding literature this is an approach that holds promise, not only for the prevention of psychotic relapse, but also as a method for enhancing symptomatic recovery and improved social functioning. Therefore, a pragmatic clinical trial with random allocation and prospective followup, was designed to evaluate whether CBT delivered on the appearance of prodromal early signs of psychotic relapse resulted in reduced admission and relapse, and as a secondary outcome, reduced positive and negative symptoms, and improved social functioning among individuals with schizophrenia.

\section{METHOD}

\section{Procedure}

The study was conducted between June 1997 and December 2000. After obtaining ethical approval from Local Research Ethics Committees in each NHS Trust potentially eligible patients who were receiving treatment from 
local community mental health teams (CMHTs) were identified though hospital and clinic databases in two NHS Trusts in the West of Scotland (six CMHTs in Ayrshire and two CMHTs in Glasgow). The locality area for these teams included a population of approximately 460000 encompassing rural, suburban, and metropoli$\tan$ areas. The case notes of these patients were then screened, and the consultant psychiatrist was approached to give permission for the assessment of those meeting inclusion criteria at that stage. Patients were then approached to give informed written consent and, if consent was granted, were interviewed to confirm entry criteria and provide baseline assessments. Entry required that patients fulfilled DSM-IV (American Psychiatric Association, 1994) criteria for schizophrenia or a related disorder confirmed by the Structured Clinical Interview for DSMIV (First et al. 1994), were aged between 18 and 65 , were receiving antipsychotic medication, and were considered relapse prone. Patients were considered relapse prone if they had one or more of the following characteristics: (1) a history of relapse in the last 2 years; (2) their keyworker viewed them as living in a stressful environment (e.g. a home environment characterized by high levels of expressed emotion); (3) living alone or socially isolated; (4) nonadherence with antipsychotic medication (where this was viewed as problematic by the participant's keyworker and/or prescribing psychiatrist); and (5) being on a neuroleptic dosage reduction programme. Patients were excluded if they were a non-English speaker, had organic brain disorder, presence of significant learning disability, severe positive psychotic symptoms (rating of $\geqslant 5$ on the positive scale of the Positive and Negative Syndrome Scale (PANSS) (Kay et al. 1987), a primary drug or alcohol dependence disorder (based on the opinion of the key worker), or being in receipt of a concurrent psychotherapy outside the study. The sample size was calculated on the basis that a sample of 150 participants (75 per group), would have $89 \%$ power to detect at $P<0.05$ an estimated reduction in relapse/exacerbation rates from $50 \%$ (e.g. Gaebel \& Pietzcker, 1985) in the TAU alone group to $25 \%$ in the CBT group (Pocock, 1996).

Participants were consecutively assessed by a research psychiatrist (M.O'G, R.S.) or a clinical psychologist (C.W.) and recruited into the study prior to randomization. After the interview the patient was randomized according to predetermined envelopes containing the treatment group to which participants would be allocated (TAU or CBT) devised by one of the authors (K.P.), which was unbeknown to the assessors, therapist or participants. No restrictions were placed on the randomization procedure with regards to any particular demographic or clinical variables. A member of the research team (L.M., J.R. or A.G.) opened an envelope that informed as to which group individual participants were to be allocated. Another member of the team witnessed this procedure, and the envelope was placed in the participant's casefile. Two research nurses (L.M. and J. R.), who were not blind to the treatment allocation of participants, conducted follow-up assessments. In addition, the research nurses undertook regular monthly liaison with the participants' treatment teams to determine if there was evidence of a relapse. If there was evidence of a relapse, the participant was seen by the research nurse using the standardized psychiatric interview (Kay et al. 1987) prior to the next planned assessment date $(12,26$, or 52 weeks) to date the relapse accurately. For participants who dropped out of the study, data on admission were taken from the case notes. The research nurse also fed back on progress of participants receiving CBT and their early signs monitoring. If a participant did not return early signs, the research nurse would check with the participant's keyworker regarding any symptom changes or circumstances/ stressors, which were suggestive of an increase in relapse risk. If there was an increase in relapse risk, the research nurse informed the therapist who then contacted the patient to conduct an assessment for targeted CBT.

\section{Assessments}

Assessments were carried out at entry, 12, 26 and 52 weeks using a battery of measures. Positive and negative symptoms were measured using the PANSS (Kay et al. 1987). The PANSS is a 30 -item observer rated scale. Each item is rated on a severity scale ranging from 1 (absence of psychopathology) to 7 (extremely severe). The sum of the first seven items constitutes the positive scale score (range 7 to 49 ): delusions, 
conceptual disorganisation, hallucinatory behaviour, excitement, grandiosity, suspiciousness/ persecution and hostility. The sum of items 8 to 14 constitutes the negative scale score (e.g. blunted affect, emotional withdrawal). The sum of items 15 to 30 constitutes the global psychopathology scale score (e.g. somatic concern, anxiety). The raters were trained using interviews with patients, either face to face or on video. Interclass correlations for the positive, negative and global subscales were 0.91 , $0.87,0.72$ respectively and for the total score $0 \cdot 80$. Relapse was defined as an admission to hospital or an increase in psychotic symptoms for minimum of 7 days. An increase in positive symptoms was based on participants' positive symptoms rated at entry on the positive scale of PANSS. Those who scored $\geqslant 3$ (mild to moderate) on any one item of the positive scale of the PANSS classified as having residual symptoms; all other participants were classified as having minimal or no residual positive symptoms. For those with residual symptoms, a $50 \%$ increase in the positive scale score, sustained for at least 1 week, was defined as meeting criteria for relapse. For those without residual symptoms, an increase in positive symptoms (rated $\geqslant 3$ ), sustained for at least 1 week, was defined as meeting criteria for a relapse. Psychological distress was measured using the Brief Symptom Inventory (BSI) (Derogatis \& Melisaratos, 1983). Negative appraisals of psychosis were assessed using the Personal Beliefs about Illness Questionnaire (PBIQ) (Birchwood et al. 1993). The Rosenberg Self-Esteem Scale (RSES) (Rosenberg, 1965) was selected as a measure of negative appraisals of self. The Social Functioning Scale (SFS) (Birchwood et al. 1990) was used to assess social role and behavioural functioning across seven basic areas of community functioning: social engagement, interpersonal behaviour, prosocial activities, recreation, independence (performance and competence) and employment. A criterion of clinical significance was used to define whether or not a participant achieved clinically significant improvement or deterioration in their social functioning defined as whether an individual's outcome response fell outside the range of the population by two standard deviations (higher or lower) from the pre-treatment baseline score (Jacobson \& Truax, 1991). In addition, medication and psychiatric care usage was monitored during the 12-month follow-up period. Total dose of antipsychotic medication at each assessment was calculated as chlorpromazine equivalents in milligrams per day (Atkins et al. 1997). Type of antipsychotic medication was also noted.

\section{Treatment groups}

\section{Treatment as usual (TAU)}

All participants continued to receive their ongoing usual treatment, which was overseen by the participants' consultant psychiatrist. The core components of TAU entailed ongoing medication, regular psychiatric review, and regular follow-up from a keyworker, usually a community mental health nurse. All participants had access to a wider multidisciplinary community mental health team.

\section{Cognitive behavioural therapy}

A description of the treatment protocol has been detailed in Gumley \& Power (2000). A clinical psychologist (A.G.) provided all CBT sessions. CBT was divided into two phases. A five-session engagement phase was delivered between entry and 12 weeks. An intensive targeted phase ( 2 to 3 sessions per week) was delivered at the appearance of early signs of relapse.

Engagement began with a description of the cognitive model of relapse (Birchwood, 1995; Gumley et al. 1999), which emphasized how the early signs of relapse (e.g. racing thoughts, unusual experiences, suspiciousness) can trigger negative beliefs concerning relapse (e.g. 'I'm going to be relapse and end up in hospital'). An explanation of how these beliefs lead to increased fear, depression or helplessness and potentially unhelpful coping behaviours (e.g. withdrawal, avoidance of services, substance use) was given. Participants were encouraged to test this model of relapse through discussion of their own prior experiences. Participants who were reluctant to accept that they had an illness were still encouraged to consider their experience of relapse, particularly in terms of prior hospital admissions. An individualized case formulation of the cognitive behavioural factors associated with relapse, and an idiosyncratic early signs monitoring questionnaire incorporating these factors was developed (Tait et al. 2002). An assistant psychologist or trial 
secretary, who were not involved in the assessment of outcome, dispatched the questionnaires to participants on a fortnightly basis. Participants were instructed to complete and return their questionnaires using a stamped addressed envelope enclosed for their use. Early signs monitoring continued for the duration of the trial. This early signs monitoring procedure was associated with an adherence rate of $83 \%$.

Targeted CBT was initiated when there was an increase in a participant's self-reported early signs. Assessment for targeting was initiated if there was a failure to return early signs questionnaires on more than one consecutive occasion and if treatment teams reported symptom changes or circumstances/stressors, which were suggestive of an increase in relapse risk. Targeted CBT began with a detailed assessment of the evidence for and against emerging relapse, in order to identify potential false alarms and to provide a test of the case formulation. Thereafter, the order of treatment tasks was as follows: identify and target beliefs and behaviours that increased risk to self or others; identify and target beliefs and behaviours accelerating relapse; and develop alternative beliefs and reinforce through behaviour change (Davidson, 2000). The therapist elicited any further negative beliefs concerning relapse. In order to reduce participants' fear or helplessness about relapse, early intervention was framed as an opportunity to develop mastery over an apparently uncontrollable and inevitable process. Alternative beliefs of relapse as a controllable process were developed (e.g. 'If I can learn to ignore unwanted thoughts, then I'll be less scared') and were tested using within and between session behavioural experiments. Behavioural experiments involved strengthening existing coping skills or developing novel coping strategies. Emphasis was given to developing strategies to counteract ruminative withdrawal and avoidance, to enhance coping with criticism from others, and to avoid the use of alcohol and illicit drugs. In addition cognitive and behavioural strategies were employed to reduce intrusive cognitive phenomena such as flashbacks to previous episodes through guided discovery and cognitive restructuring of problematic appraisals concerning anger, trust, helplessness, and self-blame (Resick \& Schnicke, 1993). All participants were encouraged to adhere with their antipsychotic medication. Where participants expressed concern regarding the tolerability of their medication they were encouraged to discuss this with their keyworker and consultant psychiatrist. In cases where participants did not adhere to medication, positive and negative beliefs about adherence and nonadherence were elicited and summarized. Where participants wished to continue to avoid medication this was also discussed with their consultant psychiatrist. Where possible, and in order to preserve collaboration, participants were encouraged to treat their non-adherence as a behavioural experiment. Anticipated benefits and problems were considered. Where problems were anticipated, the implementation of existing or potential coping skills was discussed, and assistance was given to participants in rehearsing and implementing these. In addition, as part of this experimental approach to treatment thresholds for reinitiating medication were agreed.

Based on participants' ratings of their early signs questionnaire targeted CBT was terminated when these ratings of early signs had reduced to baseline levels. Targeted CBT was concluded by a review of strategies employed during treatment, and an examination of the evidence for and against participants' negative beliefs and their alternative beliefs concerning relapse.

\section{Statistical analysis}

All analyses were according to the intentionto-treat principle. Baseline characteristics were summarized as number of subjects $(\%)$ for categorical covariates and mean (standard deviation) for continuous covariates. For the statistical models that used baseline covariates as adjusting factors, missing data on these covariates were imputed using the conditional mean based on centre, sex and age. The primary outcomes of time to first hospital admission and time to first relapse were displayed using Kaplan-Meier survival plots, and the difference between the two treatment groups estimated using Cox proportional hazards models. This treatment effect was adjusted for baseline covariates listed in Table 1. The secondary outcomes of change over baseline at 12 months in PANSS components (positive, negative, global), and the components of Social Functioning Scores (withdrawal, interpersonal, independence performance, independence competence, 
Table 1. Baseline characteristics by randomized treatment group. Data shown are number of subjects (\%) for categorical data, mean (standard deviation) for continuous data

\begin{tabular}{|c|c|c|c|}
\hline Factor & Level/units & $\mathrm{CBT}$ & TAU \\
\hline Age & years & $35 \cdot 8(9 \cdot 6)$ & $36 \cdot 7(10 \cdot 1)$ \\
\hline Sex & $\begin{array}{l}\text { Male } \\
\text { Female }\end{array}$ & $\begin{array}{l}54(75 \cdot 0 \%) \\
18(25 \cdot 0 \%)\end{array}$ & $\begin{array}{l}51(70 \cdot 8 \%) \\
21(29 \cdot 2 \%)\end{array}$ \\
\hline Primary diagnosis & $\begin{array}{l}\text { Schizophrenia } \\
\text { Schizoaffective } \\
\text { Schizophreniform } \\
\text { Delusional disorder } \\
\text { Psychotic disorder NOS }\end{array}$ & $\begin{array}{l}59(81 \cdot 9 \%) \\
12(16 \cdot 7 \%) \\
1(1 \cdot 4 \%) \\
0(0 \%) \\
0(0 \%)\end{array}$ & $\begin{array}{c}59(81 \cdot 9 \%) \\
10(13 \cdot 9 \%) \\
1(1 \cdot 4 \%) \\
1(1.4 \%) \\
1(1.4 \%)\end{array}$ \\
\hline Medication & $\begin{array}{l}\text { Atypical } \\
\text { Typical }\end{array}$ & $\begin{array}{l}41(56 \cdot 9 \%) \\
31(43 \cdot 1 \%)\end{array}$ & $\begin{array}{l}41(56 \cdot 9 \%) \\
31(43 \cdot 1 \%)\end{array}$ \\
\hline Medication dose & $\mathrm{mg} /$ day & $404(251)$ & $362(226)$ \\
\hline Centre & $\begin{array}{l}\text { Ayrshire } \\
\text { Glasgow }\end{array}$ & $\begin{array}{l}40(55 \cdot 6 \%) \\
32(44 \cdot 4 \%)\end{array}$ & $\begin{array}{l}38(52 \cdot 8 \%) \\
34(47 \cdot 2 \%)\end{array}$ \\
\hline PANSS & $\begin{array}{l}\text { Positive } \\
\text { Negative } \\
\text { Global psychopathology }\end{array}$ & $\begin{array}{l}10 \cdot 9(3 \cdot 2) \\
12 \cdot 8(4 \cdot 4) \\
31 \cdot 7(7 \cdot 5)\end{array}$ & $\begin{array}{l}10 \cdot 5(2 \cdot 7) \\
12 \cdot 6(5 \cdot 3) \\
29 \cdot 3(6 \cdot 6)\end{array}$ \\
\hline BSI & GSI & $1 \cdot 32(0 \cdot 80)$ & $1.05(0 \cdot 70)$ \\
\hline PBIQ & $\begin{array}{l}\text { Self } v \text {. Illness } \\
\text { Entrapment } \\
\text { Shame } \\
\text { Humiliation } \\
\text { Loss }\end{array}$ & $\begin{array}{r}9 \cdot 3(2 \cdot 7) \\
10 \cdot 2(2 \cdot 4) \\
7 \cdot 2(2 \cdot 1) \\
4 \cdot 5(0 \cdot 8) \\
7 \cdot 8(2 \cdot 0)\end{array}$ & $\begin{array}{r}8 \cdot 9(2 \cdot 9) \\
10 \cdot 1(2 \cdot 8) \\
7 \cdot 0(1 \cdot 8) \\
4 \cdot 6(1 \cdot 0) \\
7 \cdot 2(2 \cdot 4)\end{array}$ \\
\hline RSES & Total score & $24 \cdot 7(6 \cdot 3)$ & $22 \cdot 8(5 \cdot 4)$ \\
\hline Duration illness & months & $113(81)$ & $114(84)$ \\
\hline History relapse* & $\begin{array}{l}\text { Yes } \\
\text { No }\end{array}$ & $\begin{array}{l}37(52 \cdot 9 \%) \\
33(47 \cdot 1 \%)\end{array}$ & $\begin{array}{l}38(56 \cdot 7 \%) \\
29(43 \cdot 3 \%)\end{array}$ \\
\hline History admission* & $\begin{array}{l}\text { Yes } \\
\text { No }\end{array}$ & $\begin{array}{l}27(38 \cdot 6 \%) \\
43(61 \cdot 4 \%)\end{array}$ & $\begin{array}{l}35(52 \cdot 2 \%) \\
32(48 \cdot 8 \%)\end{array}$ \\
\hline SFS & $\begin{array}{l}\text { Withdrawal } \\
\text { Interpersonal } \\
\text { Performance } \\
\text { Competence } \\
\text { Recreation } \\
\text { Prosocial } \\
\text { Employment }\end{array}$ & $\begin{array}{r}9 \cdot 3(2 \cdot 5) \\
6 \cdot 5(1 \cdot 9) \\
26 \cdot 1(6 \cdot 7) \\
34 \cdot 9(3 \cdot 9) \\
14 \cdot 7(6 \cdot 1) \\
12 \cdot 6(8 \cdot 3) \\
3 \cdot 0(3 \cdot 0)\end{array}$ & $\begin{array}{r}9 \cdot 7(2 \cdot 4) \\
6 \cdot 6(2 \cdot 0) \\
27 \cdot 0(6 \cdot 2) \\
36 \cdot 0(3 \cdot 4) \\
13 \cdot 7(5 \cdot 5) \\
12 \cdot 0(6 \cdot 3) \\
2 \cdot 9(3 \cdot 1)\end{array}$ \\
\hline
\end{tabular}

PANSS, Positive and Negative Syndrome Scale; BSI, Brief Symptom Inventory; PBIQ, Personal Beliefs about Illness Questionnaire; RSES, Rosenberg Self-Esteem Scale; SFS, Social Functioning Scale; GSI, Global Severity Index; NOS, not otherwise specified.

* Two years pre-entry.

recreation, employment), and the equivalent chlorpromazine dose, were compared between the two treatments using normal linear models, with and without adjustment for baseline covariates as above. In addition, amount of treatment received and number of days in hospital were summarized for each treatment group. Clinically significant changes in the Social Functioning Scores were defined as any movement of at least plus (higher) or minus (lower) 2 sample standard deviations (calculated without imputation of missing data) from 12 months over baseline. The number of subjects with a lower change, and then an upper change, was then compared between the two groups using Fisher Exact tests. The number of participants needed to be treated for 1 year to avert 1 event was defined as the reciprocal of the difference in the raw event rates between the TAU and CBT groups. No adjustment has been made for multiple testing. All analyses performed using SAS 8.2 for Windows NT.

\section{RESULTS \\ Patient characteristics}

The flow of participants into the study is illustrated in Fig. 1. A total of 144 participants were 


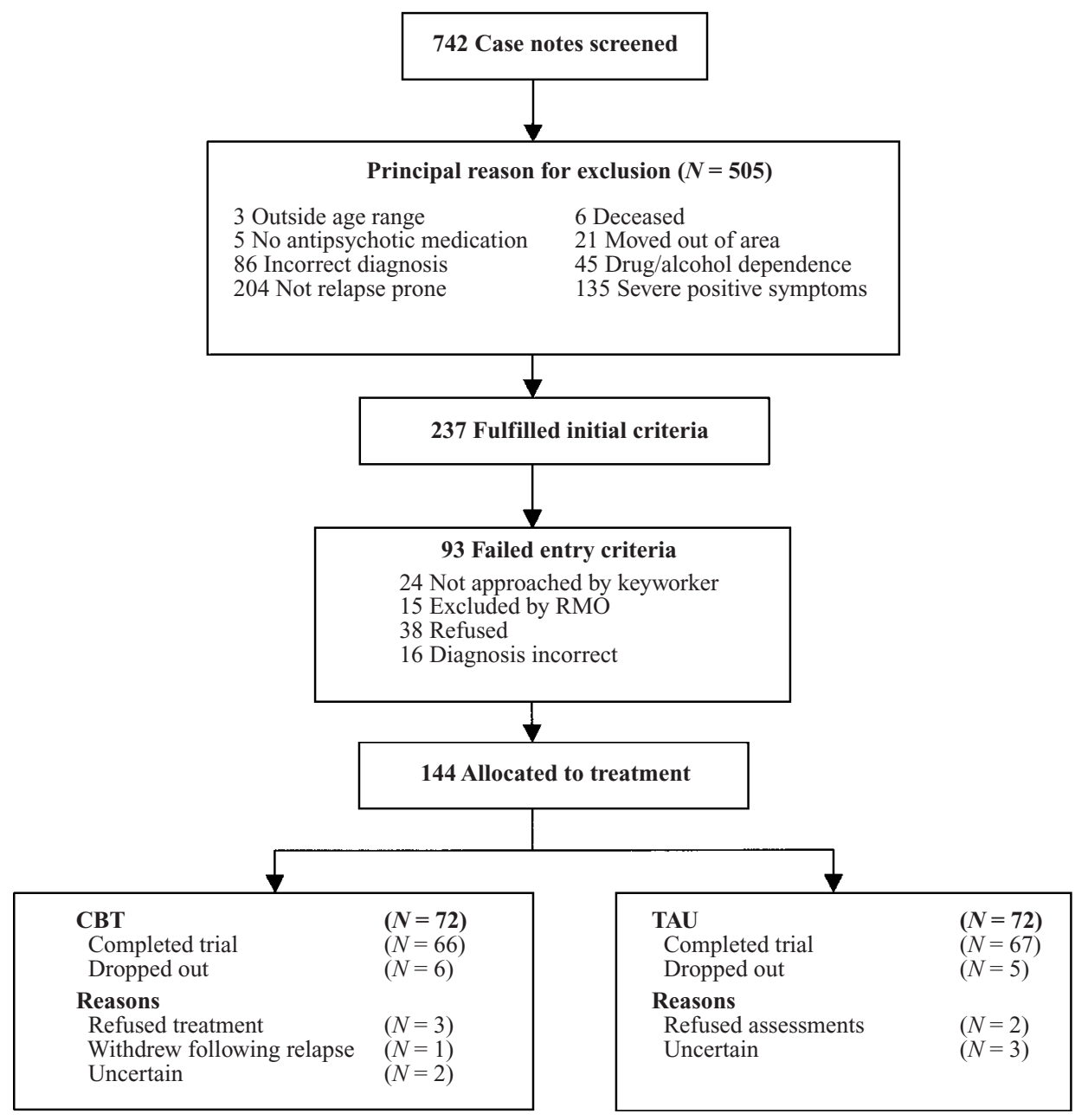

FIG. 1. Recruitment and allocation of participants.

randomized to CBT $(N=72)$ or TAU $(N=72)$. Table 1 shows the baseline characteristics of study participants. There were no appreciable differences between the CBT and TAU groups except that the CBT group had a seemingly lower self-esteem as measured by the Rosenberg Self-Esteem Scale.

\section{Treatment received during study period}

During the study period the CBT group received a median (range) 6 (0-14) number of out-patient medical consultations and $28 \cdot 5(0-86)$ number of community mental health team contacts. The TAU group received a median (range) 7 (0-21) number of out-patient medical consultations and $27 \cdot 5(0-100)$ number of community mental health team contacts. The CBT group received an additional median (range) of 5 (0-6) engagement sessions between entry and 12 weeks. Twenty-eight CBT participants received a median (range) of 5 (2-16) number of targeted CBT sessions.

\section{Admission/relapse}

The Kaplan-Meier plot of time to admission is illustrated in Fig. 2. During the study period 11 $(15 \cdot 3 \%)$ participants in the CBT group were admitted to hospital compared to $19(26.4 \%)$ of the TAU group (hazard ratio $(\mathrm{HR})=0.53$, $P=0 \cdot 089,95 \%$ CI $0 \cdot 25,1 \cdot 10, \mathrm{NNT}=9)$. Following adjustment for the baseline variables shown in Table 1 the difference between the 


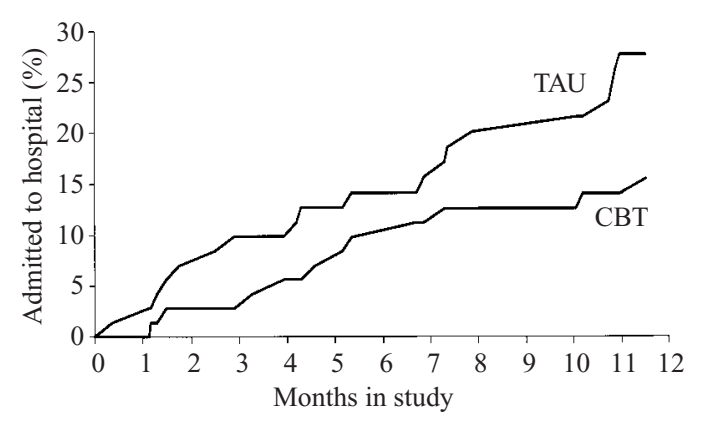

FIG. 2. Kaplan-Meier plot of time to hospital admission for cognitive behaviour therapy (CBT) and treatment as usual (TAU).

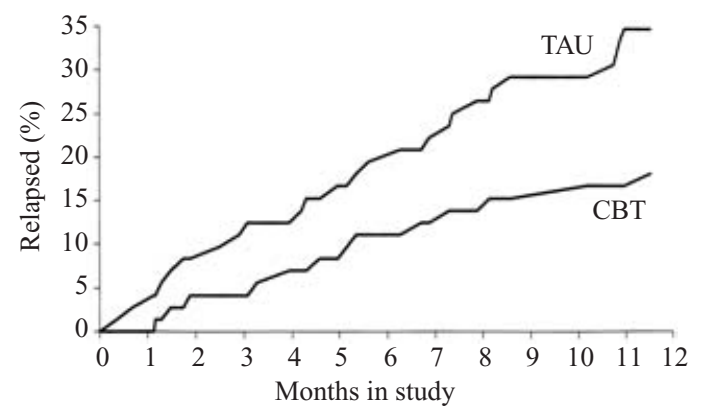

FIG. 3. Kaplan-Meier plot of time to relapse for cognitive behaviour therapy (CBT) and treatment as usual (TAU).

randomized treatment groups in reduction in admission to hospital reduced further and became statistically significant $(\mathrm{HR}=0 \cdot 29$, $P=0 \cdot 032,95 \%$ CI $0 \cdot 09,0 \cdot 90)$. In addition, CBT participants had a total of 917 days spent in hospital compared to 1694 days for TAU participants. The Kaplan-Meier plot of time to relapse is illustrated in Fig. 3. A total of 13 $(18 \cdot 1 \%)$ participants in CBT relapsed compared to $25(34.7 \%)$ in TAU $(\mathrm{HR}=0 \cdot 47, P=0 \cdot 028$, $95 \%$ CI $0 \cdot 24,0.92, \mathrm{NNT}=6$ ). Following adjustment for baseline variables as above the reduction in relapse between the treatment groups reduced further $(\mathrm{HR}=0 \cdot 29, P=0 \cdot 008,95 \% \mathrm{CI}$ $0 \cdot 12,0 \cdot 73)$.

\section{Secondary outcomes}

Table 2 illustrates baseline and 12 month scores on the Positive and Negative Syndrome Scale and Social Functioning Scale for the CBT and TAU groups. The change over baseline, and then the mean difference (with $95 \% \mathrm{CI}$ ) in this change over baseline between treatment groups are also shown. At 12 months the CBT group showed greater improvement in positive symptoms $(-1 \cdot 10, P=0 \cdot 028,95 \% \mathrm{CI}-2 \cdot 08,-0 \cdot 12)$ negative symptoms $(-1 \cdot 89, P=0 \cdot 016,95 \% \mathrm{CI}$ $-3 \cdot 39, \quad-0 \cdot 35)$, global psychopathology $(-4 \cdot 34, P=0.0005,95 \%$ CI $-6.75,-1.93)$, performance of independent functions $(2 \cdot 83$, $P=0.013,95 \%$ CI $0.61,5.05)$ and prosocial activities $(4.05, P=0.0024,95 \%$ CI $1.46,6.64)$. These findings were essentially confirmed after adjustment for the relevant set of covariates listed in Table 1. Table 3 illustrates the number of participants whose magnitude of change is greater than two baseline standard deviations (lower or higher). A total of nine participants in CBT made clinically significant improvements in prosocial functioning compared to one in TAU $(P=0 \cdot 017)$.

\section{DISCUSSION}

The current study is the first to examine the effectiveness of CBT delivered as an early intervention strategy designed to prevent relapse in schizophrenia. This study differs from previous studies of CBT for schizophrenia, which have included participants on the basis of having severe and distressing positive psychotic symptoms which are resistant to antipsychotic medication (Tarrier et al. 1993, 1998; Kuipers et al. 1997; Pinto et al. 1999; Sensky et al. 2000), or participants experiencing an acute phase of psychosis (Drury et al. 1996a,b). Therefore, the interventions evaluated in these studies have principally focused on the frequency and distress of psychotic symptoms such as delusions and hallucinations, with relapse prevention as an important, albeit secondary outcome. In contrast, our study included participants who were stabilized out-patients, and whose positive symptoms had been largely responsive to previous antipsychotic treatment but who nevertheless remained relapse prone. In addition, during this study CBT was delivered as a targeted intervention at the appearance of early signs suggestive of relapse and principally focused on the modification of negative beliefs about relapse (e.g. 'I am going to relapse and have no control over what is happening to me') and the development of cognitive and behavioural coping strategies to control relapse. 


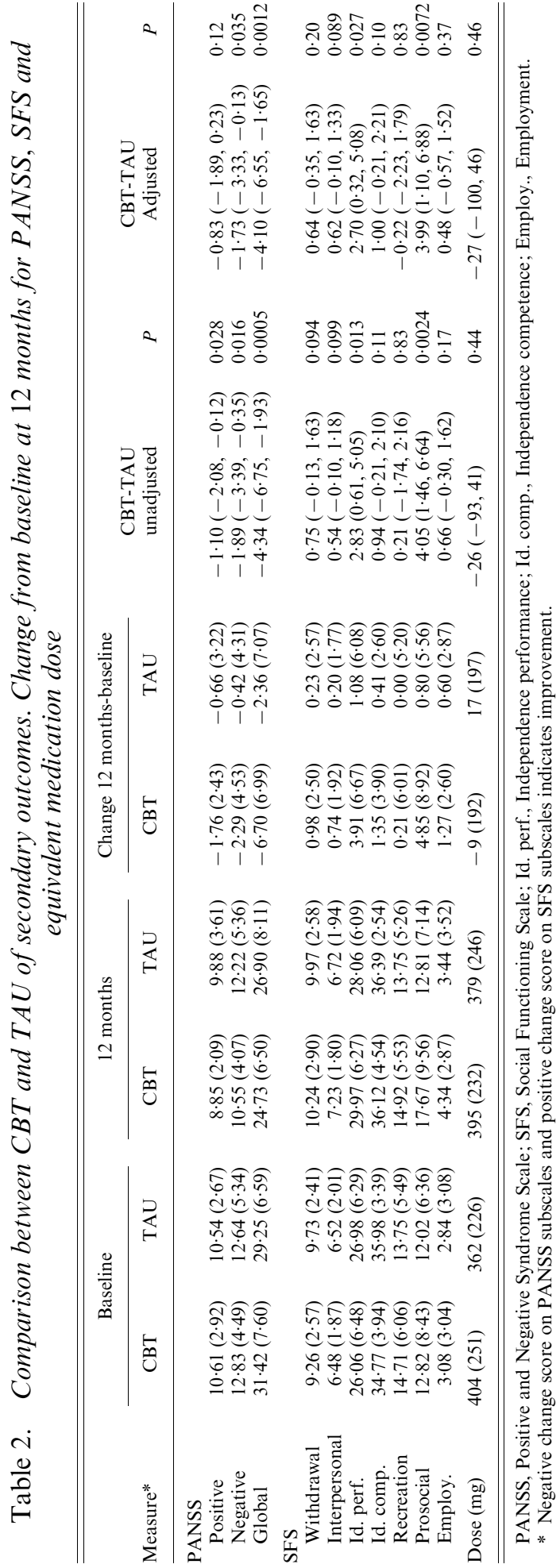

Table 3. Clinically significant changes for Social Functioning Scale components

\begin{tabular}{lcccccccc}
\hline \hline & \multicolumn{3}{c}{$\leqslant-2$ s.D. } & & \multicolumn{3}{c}{$\geqslant 2$ s.D. } \\
\cline { 2 - 4 } \cline { 6 - 8 } SFS component & CBT & TAU & $P$ & & CBT & TAU & $P$ \\
\hline Withdrawal & 1 & 2 & $0 \cdot 62$ & 4 & 3 & $1 \cdot 00$ \\
Interpersonal & 0 & 1 & $0 \cdot 49$ & 6 & 1 & $0 \cdot 12$ \\
Performance & 0 & 2 & $0 \cdot 24$ & 7 & 3 & $0 \cdot 32$ \\
Competence & 1 & 0 & $1 \cdot 00$ & 3 & 1 & $0 \cdot 62$ \\
Recreation & 1 & 1 & $1 \cdot 00$ & 1 & 1 & $1 \cdot 00$ \\
Pro-social & 1 & 0 & $1 \cdot 00$ & 9 & 1 & $0 \cdot 017$ \\
Employ & 0 & 0 & $1 \cdot 00$ & 4 & 5 & $0 \cdot 74$ \\
\hline
\end{tabular}

Data shown are number of subjects whose magnitude of change over baseline at 12 months is greater than two baseline standard deviations, lower or higher $(\leqslant-2$ s.D. or $\geqslant 2$ s.D.). $P$ values given are for Fisher Exact Tests for comparing the number of subjects lower than -2 s.D.s below baseline between the two treatment groups, and also for the number higher than 2 s.D. above baseline.

The results of this study indicate that targeting CBT during the early stages of relapse results in reduced relapse rate $(18.1 \%$ versus $34.7 \%)$ but not admission rates $(15.3 \%$ versus $26.4 \%$ ) over 12 -months. The failure to detect a statistically significant difference in admission rates between CBT and TAU may well be due to the sample size of the study. In calculating the sample size necessary for the study we hypothesized a proportional change of $50 \%$ in the proportion of participants with a relapse. Our findings were in line with this hypothesis. However, based on previous research (Gaebel \& Pietzcker, 1985) we assumed an underlying relapse rate of $50 \%$ in TAU. Our findings on relapse and admission in TAU were less than what we had originally expected. This may be due to the nature of TAU itself. In the main participants in both arms of the study were seen on a fortnightly basis by their community-based key workers, usually psychiatric nurses and on a bi-monthly basis by their psychiatrist. Therefore, in routine care, key workers may well have being identifying and responding to early signs of relapse. In a recent study by Herz et al. (2000) 82 participants were randomized to either Treatment as Usual (TAU) or an experimental group: 'Program for Relapse Prevention' (PRP). PRP consisted of education on early signs for the participants and their families, active monitoring of early signs, clinical interventions within 24 to 48 hours of identification of a 'prodromal' episode which included of crisis problem solving, supportive therapy, and increased medication as required. 
In addition, weekly supportive group therapy emphasizing coping skills or supportive individual therapy sessions were offered to participants, and multifamily psychoeducation groups were offered to carers. Over 18 months, there was a significant reduction in relapse rate among the PRP group $(7 / 41,17 \%)$ compared to TAU $(14 / 41,34 \%)$. On the one hand, as the study intervention was a package designed to prevent relapse it was not possible to discern the influence of early signs monitoring and the psychological interventions alone. However, on the other hand, clinicians in PRP identified more early signs episodes before participants met objective criteria for relapse than their TAU counterparts. This supports the hypothesis that early detection (the independent variable) was successfully manipulated. In our study we did not record the number of early signs episodes identified by routine care providers and this is an important methodological limitation, which should be borne in mind in interpreting the results of our study. Furthermore, as our assessors were not blind to treatment there is the possibility that they were more sensitive to participants receiving CBT and therefore there is a problem of potential bias. For this reason hospital admission provides the best evidence of the effectiveness of this form of CBT. We attempted to maintain the independence of the assessors by relying on changes in early signs completed by the participants to initiate targeted CBT. Where early signs were not returned, assessors checked the status of participants with their respective key workers. If there were changes or circumstances suggestive of an increase in relapse risk, assessors did not recruit the participant to targeted CBT, but informed the therapist who then made contact in order to conduct an assessment for targeting. Therefore, in order to rectify these methodological shortcomings future studies would include blind assessors, and make systematic recordings of early signs episodes identified prior to objective relapse in both the experimental and control group. In addition, a study with 422 participants (211 in each group) would have $80 \%$ power to detect $(\alpha<0.05)$ a proportionate reduction in admission rates of $26 \%$ to $15 \%$ for CBT versus TAU (Pocock, 1996).

Notwithstanding these important methodological limitations, the results found in this study are comparable with other studies (Hogarty et al. 1997a, b; Linszen et al. 1998; Herz et al. 2000), which have included an individualized approach to relapse prevention in schizophrenia. Hogarty et al. $(1997 a, b)$ evaluated personal therapy (PT), a psychological treatment designed to improve control over relapse. PT involved three phases: (1) psychoeducation and the identification of affective, cognitive and physiological experience of stress; (2) stress management techniques and social skills training; and (3) skills training in managing criticism and resolving conflict. Among patients living with family PT was associated with a relapse rate of $13 \%$ over 3 years. However, among those living alone, PT led to more psychotic relapses. The authors argue that this arose because PT may have served as a stressor for those without support from their family and having to cope with living in the community alone. In particular during the study this group of participants already had high levels of stress including financial problems and conflict with staff. In our study, many of our participants were living alone, but were also stabilized and relatively well supported by their community mental health teams. On the other hand, Linszen et al. (1998) found that combined family and individual intervention was associated with a relapse rate of $15 \%$ over 12 months, however following transfer to standard services relapse rate increased in the following 2 years to $64 \%$. It is not at present known whether the effects of CBT on relapse/admission rate in our study are sustained after 12 months, and a further longer term follow-up study of participants in this trial is planned.

We also found that following adjustment for baseline covariates, the reduction in admission rate between the two randomized treatment groups was further reduced and reached statistical significance. This suggests that factors other than treatment are associated with admission to hospital with a psychotic relapse. For example, numerous factors have been found to be associated with relapse including early adolescent adjustment (Robinson et al. 1999), duration of untreated psychosis (Crow et al. 1986), non-adherence with medication (Kemp et al. 1998), expressed emotion (Kavanagh, 1992) and coping style (Hultman et al. 1997). In addition, there is evidence to suggest that 
patients themselves monitor and regulate their symptoms in order to prevent relapse (Breier \& Strauss, 1983; McCandless-Glimcher et al. 1986; Hultman et al. 1997). Indeed, our approach to treatment focused on participants' beliefs and coping responses to early signs of increased risk of relapse. Further prognostic research investigating the role of these factors in mediating risk of future relapse is merited.

Consistent with other studies of CBT (Tarrier et al. 1993, 1998; Drury et al. 1996a, b; Kuipers et al. 1997; Pinto et al. 1999; Sensky et al. 2000) patients receiving CBT had significant improvements over TAU in positive symptoms, negative symptoms and global psychopathology. However, unlike previous studies of CBT, this study also found significant improvements in two social functioning domains, performance of independent functioning (e.g. shopping, looking after money) and prosocial activities (e.g. going to the cinema, visiting family). Indeed, $12 \cdot 5 \%$ (9/72) of participants in CBT made a clinically significant improvement in their prosocial functioning; that is $\geqslant 2$ standard deviations above their baseline scores. Other treatments, which explicitly target relapse risk, have also found improvements in social functioning. For example, family intervention studies have shown that participants who receive family intervention also make improvements in their social functioning (Spiegel \& Wissler, 1987; Barrowclough \& Tarrier, 1990; Hogarty et al. 1991; Vaughn et al. 1992; Xiang et al. 1994). In studies of relapse prevention in bipolar disorder (Perry et al. 1999; Lam et al. 2000; Scott et al. 2001) significant improvements in social functioning have also been demonstrated. Drury et al. (2000) found that those who did not relapse more than once over 5 years reported increased control over psychosis. Iqbal et al. (2000) found that increased awareness of psychosis and a perception of being unable to control relapse was associated with the development of postpsychotic depression. Therefore interventions, which confer clinical stability, may reduce the fear of relapse and improve perceived control over psychosis. This may facilitate individuals adopting new or more adaptive coping strategies, which enhance social and interpersonal functioning, as opposed to using withdrawal or avoidance orientated coping (Hultman et al. 1997). Prospective research investigating the role of appraisals of relapse and coping in the recovery of social and interpersonal functioning in schizophrenia is needed.

To summarize, CBT had a beneficial effect on relapse and admission over 12 months. Additional benefits were also observed for positive symptoms, negative symptoms, and global psychopathology. In addition, improvements were found in areas of social functioning including independence and prosocial activities. Treatment seemed acceptable with only three patients refusing treatment. In addition, the rate of dropout was low in both groups. However, this was a study, which did not have blind assessors, and although these results are encouraging they should be replicated with control for the attentional effects of the CBT. There also should be longer-term follow-up to evaluate whether treatment gains achieved over 12 months are sustained.

The research was supported by a grant (K/RED/18/ 13) to Andrew Gumley and Kevin Power from the Chief Scientist Office, Scottish Executive. The views expressed in this paper are not necessarily those of the Scottish Executive. The authors are grateful to Alison Tait, Zoe Chouliara, Athanasios Karatzias, Craig White, Rupert Suckling and Margaret Maloney for their contributions and support during this project. We are also grateful to all of the patients and staff who participated in the project.

\section{REFERENCES}

American Psychiatric Association (1994). The Diagnostic and Statistical Manual of Mental Disorders, Fourth Edition. American Psychiatric Association: Washington, DC.

Atkins, M., Burgess, A., Bottomly, C. \& Riccio, M. (1997). Chlorpromazine equivalents: a consensus opinion for both clinical and research applications. Psychiatric Bulletin 21, 224-226.

Barrowclough, C. \& Tarrier, N. (1990). Social functioning in schizophrenic patients. Social Psychiatry and Psychiatric Epidemiology 25, 125-129.

Birchwood, M. (1995). Early intervention in psychotic relapse: cognitive approaches to detection and management. Behaviour Change 12, 2-19.

Birchwood, M. \& Spencer, E. (2001). Early intervention in psychotic relapse. Clinical Psychology Review 21, 1211-1226.

Birchwood, M., Smith, J., Macmillan, F., Hogg, B., Prasad, R., Harvey, C. \& Bering, S. (1989). Predicting relapse in schizophrenia: the development and implementation of an early signs monitoring system using patients and families as observers. Psychological Medicine 19, 649-656.

Birchwood, M., Smith, J., Cochrane, R., Wetton, C. \& Copestake, S. (1990). The Social Functioning Scale: the development and validation of a new scale of social adjustment for use in family intervention programmes with schizophrenic patients. British Journal of Psychiatry 157, 853-859. 
Birchwood, M., Mason, R. \& Macmillan, F. (1993). Depression, demoralisation and control over psychotic illness. Psychological Medicine 23, 387-395.

Brier, A. \& Strauss, J. S. (1983). Self control in psychiatric disorders. Archives of General Psychiatry 40, 1141-1145.

Crow, T. J., MacMillan, J. F., Johnson, A. L. \& Johnstone, E. C. (1986). The Northwick Park study of first episodes of schizophrenia. III. Short term outcome in trial entrants and trial eligible patients. British Journal of Psychiatry 148, 128-133.

Davidson, K. M. (2000). Cognitive Therapy for Personality Disorders. Butterworth-Heinemann, Oxford.

De Haan, L., Linszen, D. H. \& Gorsira, R. (1998). Early intervention, social functioning and psychotic relapse of patients with recent-onset schizophrenic disorders. International Clinical Psychopharmacology 13, 63-66.

Derogatis, L. \& Melisaratos, N. (1983). The Brief Symptom Inventory: an introductory report. Psychological Medicine 13, 595-605.

Drury, V., Birchwood, M., Cochrane, R. \& Macmillan, F. (1996a). Cognitive therapy and recovery from acute psychosis: a controlled trial. I. Impact on psychotic symptoms. British Journal of Psychiatry 169, 593-601.

Drury, V., Birchwood, M., Cochrane, R. \& Macmillan, F. (1996b). Cognitive therapy and recovery from acute psychosis: a controlled trial. II. Impact on recovery time. British Journal of Psychiatry 169, 602-607.

Drury, V., Birchwood, M. \& Cochrane, R. (2000). Cognitive therapy and recovery from acute psychosis: a controlled trial. 3. Five-year follow-up. British Journal of Psychiatry 177, 8-14.

First, M. B., Spitzer, R. L., Gibbon, M. \& Williams, J. B. W. (1994). Structured Clinical Interview for DSM-IV Axis I Disorders (SCID). New York State Psychiatric Institute, Biometrics Research: New York.

Gaebel, W. \& Pietzcker, A. (1985). One year outcome of schizophrenic patients: interaction of chronicity and neuroleptic treatment. Pharmacopsychiatry 18, 235-239.

Gaebel, W., Frick, U., Kopcke, W., Linden, M., Muller, P., MullerSpahn, F., Pietzcker, A. \& Tegeler, J. (1993). Early neuroleptic intervention in schizophrenia: are prodromal symptoms valid predictors of relapse? British Journal of Psychiatry 163 (Suppl. 21), 8-12.

Gumley, A. I. \& Power, K. G. (2000). Is targeting cognitive therapy during early relapse in psychosis feasible? Behavioural and Cognitive Psychotherapy 28, 161-174.

Gumley, A. I., White, C. A. \& Power, K. G. (1999). An interacting cognitive subsystems model of relapse and course of psychosis. Clinical Psychology and Psychotherapy 6, 261-278.

Herz, M. I., Lamberti, J. S., Mintz, J., Scott, R., O'Dell, S. P., McCartan, L. \& Nix, G. (2000). A programme for relapse prevention in schizophrenia: a controlled study. Archives of General Psychiatry 57, 277-283.

Hogarty, G. E., Anderson, C. M., Reiss, D. J., Kornblith, S. J., Greenwald, D., Ulrich, R. F. \& Carter, M. (1991). Family psychoeducation, social skills training, and maintenance chemotherapy in the aftercare treatment of schizophrenia. Archives of General Psychiatry 48, 340-347.

Hogarty, G. E., Kornblith, S. J., Greenwald, D., DiBarry, A. L., Cooley, S., Ulrich, R. H., Carter, M. \& Flesher, S. (1997a). Three year trials of personal therapy among schizophrenic patients living with or independent of family. I. Description of study and effects on relapse rates. American Journal of Psychiatry 154, 1504-1513.

Hogarty, G. E., Greenwald, D., Ulrich, R. H., Kornblith, S. J., DiBarry, A. L., Cooley, S., Carter, M. \& Flesher, S. (1997b). Three year trials of personal therapy among schizophrenic patients living with or independent of family. II. Effects on adjustment of patients. American Journal of Psychiatry 154, 1514-1524.

Hultman, C. M., Weiselgren, I.-M. \& Ohman, A. (1997). Relationships between social support, social coping and life events in the relapse of schizophrenic patients. Scandinavian Journal of Psychology 38, 3-13.

Iqbal, Z., Birchwood, M., Chadwick, P. \& Trower, P. (2000). Cognitive approach to depression and suicidal thinking in psychosis.
2. Testing the validity of the social ranking model. British Journal of Psychiatry 177, 522-528.

Jacobson, N. S. \& Truax, P. (1991). Clinical significance: a statistical approach to defining meaningful change in psychotherapy research. Journal of Consulting and Clinical Psychology 59, 12-19.

Jolley, A. G., Hirsch, S. R., Morrison, E., McRink, A. \& Wilson, L. (1990). A trial of brief intermittent neuroleptic prophylaxis for selected schizophrenic outpatients: clinical and social outcome at two years. British Medical Journal 301, 837-842.

Jorgensen, P. (1998). Early signs of psychotic relapse in schizophrenia. British Journal of Psychiatry 172, 327-330.

Kavanagh, D. (1992). Recent developments in expressed emotion and schizophrenia. British Journal of Psychiatry 37, 51-56.

Kay, S., Fizbein, A. \& Opler, L. (1987). The Positive and Negative Syndrome Scale (PANSS) for Schizophrenia. Schizophrenia Bulletin 13, 261-275.

Kemp, R., Kirov, B., Everitt, B., Hayward, P. \& David, A. (1998). Randomised controlled trial of compliance therapy; 18-month follow-up. British Journal of Psychiatry 172, 413-419.

Kuipers, E., Garety, P., Fowler, D., Dunn, G., Bebbington, P., Freeman, D. \& Hadley, C. (1997). London-East Anglia randomised controlled trial of cognitive-behavioural therapy for psychosis. II: effects of the treatment phase. British Journal of Psychiatry 171, 319-327.

Kuipers, E., Fowler, D., Garety, P., Chisolm, D., Freeman, D., Dunn, G., Bebbington, P. \& Hadley, C. (1998). London-East Anglia randomised controlled trial of cognitive-behavioural therapy for psychosis. III: follow-up and economic evaluation at 18 months. British Journal of Psychiatry 173, 61-68.

Lam, D. H. \& Wong, G. (1997). Prodromes, coping strategies, insight and social functioning in bipolar affective disorders. Psychological Medicine 27, 1091-1100.

Lam, D. H., Bright, J., Jones, S., Hayward, P., Schuck, N., Chisholm, D. \& Sham, P. (2000). Cognitive therapy for bipolar illness - a pilot study of relapse prevention. Cognitive Therapy and Research 24, 403-520.

Lam, D. H., Wong, G. \& Sham, P. (2001). Prodromes, coping strategies and the course of illness in bipolar affective disorder - a naturalistic study. Psychological Medicine 31, 1397-1402.

Linszen, D. H., Dingemans, P. M. A. J., Lenior, M. E., Scholte, W. F., De Haan, L. \& Goldstein, M. J. (1998). Early detection and intervention in schizophrenia. International Clinical Psychopharmacology 13, 31-34.

McCandless-Glincher, L., McKnight, S., Hamera, E., Smith, B. L., Paterson, K. \& Plumlee, A. A. (1986). Use of symptoms by schizophrenics to monitor and regulate their illness. Hospital and Community Psychiatry 37, 929-933.

Marder, S. R., Mintz, J., Van Putten, T., Lebell, M., Wirshing, W. C. \& Johnson-Cronk, K. (1991). Early prediction of relapse in schizophrenia: an application of receiver operating characteristic (ROC) methods. Psychopharmacology Bulletin 27, 79-82.

Marder, S. R., Wirshing, W. C., Van Putten, T., Mintz, J., McKenzie, J., Johnson-Cronk, K., Lebell, M. \& Liberman, R. P. (1994). Fluphenazine vs placebo supplementation for prodromal signs of relapse in schizophrenia. Archives of General Psychiatry 51, 280-287.

Perry, A., Tarrier, N., Morriss, R., McCarthy, E. \& Limb, K. (1999). Randomised controlled trial of efficacy of teaching patients with bipolar disorder to identify early symptoms of relapse and obtain treatment. British Medical Journal 318, 149-153.

Pinto, A., La Pia, S., Manella, R., Giorgio, D. \& DiSimone, L. (1999). Cognitive behavioural therapy and clozapine for clients with treatment refractory schizophrenia. Psychiatric Services 50, 901-904.

Pocock, S. J. (1996). Clinical Trials: A Pragmatic Approach. John Wiley \& Sons: Chichester.

Resick, P. A. \& Schnicke, M. K. (1993). Cognitive Processing Therapy for Rape Victims: A Treatment Manual. Sage: California.

Robinson, D., Woerner, M. G., Alver, J., Bilder, R., Goldman, R., Geisler, S., Koreen, A., Sheitman, B., Chakos, M., Mayerhoff, D. \& Leiberman, J. (1999). Predictors of relapse following response 
from a first episode of schizophrenia or schizoaffective disorder. Archives of General Psychiatry 56, 241-247.

Rosenberg, M. (1965). Society and the Adolescent Self-Image. Princeton University Press: Princeton, NJ.

Scott, J., Garland, A. \& Moorhead, S. (2001). A pilot study of cognitive therapy in bipolar disorders. Psychological Medicine 31, 459-467.

Sensky, T., Turkington, D., Kingdon, D., Scott, J. L., Scott, J., Siddle, R., O'Carroll, M. \& Barnes, T. R. E. (2000). A randomised controlled trial of cognitive behavioural therapy in schizophrenia resistant to medication. Archives of General Psychiatry 57, $165-172$.

Shepherd, M., Watt, D., Falloon, I. \& Smeeton, N. (1989). The natural history of schizophrenia: a five year follow-up study of outcome and prediction in a representative sample of schizophrenics. Psychological Medicine. Monograph Supplement 15, page 46. Cambridge University Press: Cambridge.

Speigel, G. \& Wissler, T. (1987). Using family consultation as a psychiatric aftercare for schizophrenic patients. Hospital and Community Psychiatry 38, 1096-1099.

Subotnik, K. L. \& Nuechterlein, K. H. (1988). Prodromal signs and symptoms of schizophrenic relapse. Journal of Abnormal Psychology 97, 405-412.

Tait, A., McNay, L., Gumley, A. I. \& O'Grady, M. (2002). The development and implementation of an idiosyncratic early signs monitoring system. Journal of Mental Health 11, 141-153.

Tarrier, N., Barrowclough, C. \& Bamrah, J. S. (1991). Prodromal symptoms of relapse in schizophrenia. Social Psychiatry and Psychiatric Epidemiology 26, 157-161.

Tarrier, N., Beckett, R., Harwood, S., Baker, A., Yusupoff, L. \& Ugarteburu, I. (1993). A trial of two cognitive-behavioural methods of treating drug-residual psychotic symptoms in schizophrenic patients: outcome. British Journal of Psychiatry 162, $524-532$.

Tarrier, N., Yusupoff, L., Kinney, C., McCarthy, E., Gledhill, A., Haddock, G. \& Morris, J. (1998). Randomised controlled trial of intensive cognitive behaviour therapy for patients with chronic schizophrenia. British Medical Journal 317, 303-307.

Tarrier, N., Wittkowsky, A., Kinney, C., McCarthy, E., Morris, J. \& Humphreys, L. (1999). Durability of the effects of cognitivebehavioural therapy in the treatment of chronic schizophrenia: 12-month follow-up. British Journal of Psychiatry 174, 500-504.

Tarrier, N., Kinney, C., McCarthy, E., Humphreys, L. \& Wittkowsky, A. (2000). Two-year follow-up of cognitive-behavioural therapy and supportive counselling in the treatment of persistent symptoms in chronic schizophrenia. Journal of Consulting and Clinical Psychology 68, 917-922.

Turkington, D., Kingdon, D., Turner, T. \& Insight into Schizophrenia Research Group (2002). Effectiveness of a brief cognitive-behavioural therapy intervention in the treatment of schizophrenia. British Journal of Psychiatry 18, 523-527.

Vaughn, K., Doyle, M., McConaghy, N., Blaszczynski, A., Fox, A. \& Tarrier, N. (1992). The relationship between relatives expressed emotion and schizophrenic relapse: an Australian application. Social Psychiatry and Psychiatric Epidemiology 27, $10-15$.

Wiersma, D., Nienhuis, F. J., Sloff, C. J. \& Giel, R. (1998). Natural course of schizophrenic disorders: a 15-year follow-up of a Dutch incidence cohort. Schizophrenia Bulletin 24, 75-85.

Xiang, M., Ran, M. \& Li, S. (1994). A controlled evaluation of psychoeducational family intervention in a rural Chinese community. British Journal of Psychiatry 165, 544-548. 